\title{
LOIT REINTAM 70
}

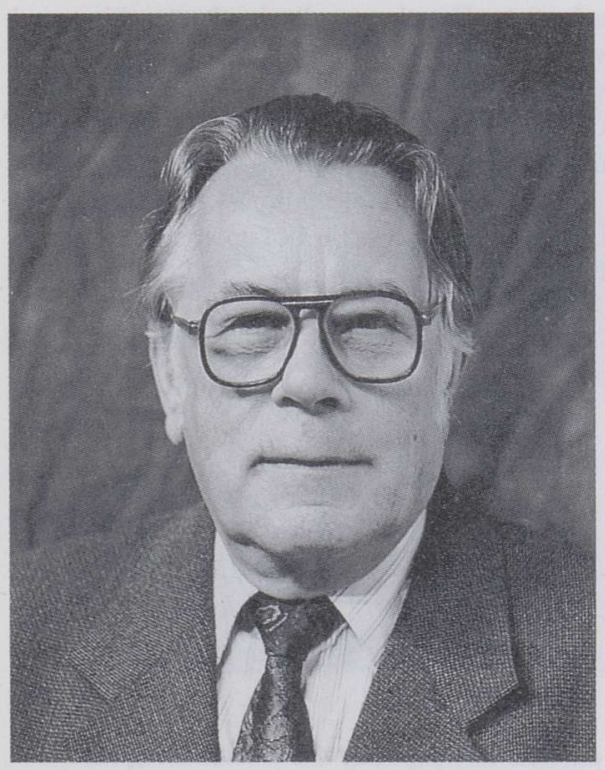

Loit Reintam, Professor Emeritus, Doctor of Biology, Member of the Estonian Academy of Sciences, former head of the Department of Soil Science and Agrochemistry of Estonian Agricultural University, was born in Tallinn on 12 November 1929 . He began his education at Nõmme High School and continued at the Faculty of Agriculture of Tartu State University, later at the Faculty of Agricultural Sciences of the Estonian Agricultural Academy, which he graduated cum laude with a diploma of learned agronomist. In 1960 he obtained the Candidate of Sciences (PhD) degree. His thesis dealt with the soils in the southeastern part of Estonia. The scientific research continued with the explanation of the soil functions related to the automorphic soil formation and the migration of substances in the soil profile.

In 1974 L. Reintam was awarded the DSc degree in biology. In his thesis he worked out a new classification of Estonian soils, the pivot of which was the genetic-lithological base, beginning with the Rendzina, over to the Brown and Pseudopodzolic up to the Podzols. The thesis presented new approaches concerning the genesis of soils, the composition and properties of humus, and the mutual relationship between the transformation products of the soil organic matter and the mineral part of the soil. He gained popularity and high support among scientists in the former Soviet Union.

L. Reintam became professor in 1977, honorary scientist in 1989 , and Member of the Estonian Academy of Sciences in 1990. He has been and is currently a member of many international and national scientific bodies.

L. Reintam is, undoubtedly, a very versatile scientist. He is the author of about 500 publications. The main topics are the genesis and diagnostics of soils, composition and properties of soil, soil organic matter, classification of soils, modernization of Estonian soil classification, ecology and protection of soils, functioning of soils, etc. A lot of his papers are closely related to geology.

Under his supervision, 2 doctor's dissertations, 6 master's theses, and 70 diploma works have been completed. He has always been willing to share his rich store of knowledge and experience needed for practical investigation of soils with his students, nonresident students, graduate students of soil science, and colleagues working in related fields of study. Through them, he has kept himself well informed about the acute problems 
of Estonian agriculture and sustainable way of management. Firmness and punctuality towards himself and towards his students are a definite part of his teachings. Depending upon the situation, he can be an inspiring and assisting colleague, or a strict critic. His work as head of department (1965-92) was determined and many-sided, including establishment and modernization of the teaching and methodological activities of the Department of Soil Science and Agrochemistry.

Special attention deserve L. Reintam's activities as Vice-President of the former All-Union Society of Soil Science and as Chairman of the Estonian Branch of the same organization. His expeditions and scientific trips have taken him to the Soviet Far East (1961, 1971, 1991), Siberia $(1961,1965,1973-$ 89), Central Russia (1963), Moldova (1962, 1984), Romania (1964), Germany (1966, 1986, 1991, 1996), Canada (1978), India (1982), Poland $(1968,1993)$, the Ukraine $(1962,1964$,
1982, 1983, 1985), Kazakhstan (1971, 1988), Mexico (1994), Indonesia (1995), Switzerland (1996), etc. These trips and wide international contacts have kept him well informed about the topical problems related to the soil science all over the world.

L. Reintam has actively participated in the work of the Estonian Science Foundation in the fields of agriculture, biology, and geology. $\mathrm{He}$ has made a great contribution to developing the soil science and organizing conferences on soil protection and ecology. His work as a reviewer and expert is impressive.

L. Reintam is an authority for all Estonian scientists. For the results in the teaching and scientific research and for his involvement in social activities he was awarded the 3rd Class Order of the White Star at the 80th anniversary of the Republic of Estonia.

Friends and colleagues congratulate Prof. Loit Reintam and wish him great success in his future activities.

Anto RAUKAS 